\title{
Effectiveness of steam inhalation and nasal irrigation for chronic or recurrent sinus symptoms in primary care: a pragmatic randomized controlled trial
}

\author{
Paul Little MBBS, Beth Stuart PhD, Mark Mullee MSc, Tammy Thomas BSc, Sophie Johnson BSc, \\ Gerry Leydon PhD, David Rabago MD, Samantha Richards-Hall BSc, Ian Williamson MD, Guiqing Yao PhD, \\ James Raftery PhD, Shihua Zhu PhD, Michael Moore MSc; for the SNIFS Study Team
}

Competing interests: None declared.

This article has been peer reviewed.

Accepted: May 13, 2016 Online: July 18, 2016

Correspondence to: Paul Little,p.little@soton.ac.uk

CMAJ 2016. DOI:10.1503/ cmaj.160362

\begin{abstract}
Background: Systematic reviews support nasal saline irrigation for chronic or recurrent sinus symptoms, but trials have been small and few in primary care settings. Steam inhalation has also been proposed, but supporting evidence is lacking. We investigated whether brief pragmatic interventions to encourage use of nasal irrigation or steam inhalation would be effective in relieving sinus symptoms.
\end{abstract}

Methods: We conducted a pragmatic randomized controlled trial involving adults (age 18-65 yr) from 72 primary care practices in the United Kingdom who had a history of chronic or recurrent sinusitis and reported a "moderate to severe" impact of sinus symptoms on their quality of life. Participants were recruited between Feb. 11, 2009, and June 30,2014, and randomly assigned to 1 of 4 advice strategies: usual care, daily nasal saline irrigation supported by a demonstration video, daily steam inhalation, or combined treatment with both interventions. The primary outcome measure was the Rhinosinusitis Disability Index (RSDI). Patients were followed up at 3 and 6 months. We imputed missing data using multiple imputation methods.
Results: Of the 961 patients who consented, 871 returned baseline questionnaires ( 210 usual care, 219 nasal irrigation, 232 steam inhalation and 210 combined treatment). A total of $671(77.0 \%)$ of the 871 participants reported RSDI scores at 3 months. Patients' RSDI scores improved more with nasal irrigation than without nasal irrigation by 3 months (crude change -7.42 v. -5.23 ; estimated adjusted mean difference between groups -2.51 , $95 \%$ confidence interval -4.65 to -0.37 ). By 6 months, significantly more patients maintained a 10-point clinically important improvement in the RSDI score with nasal irrigation ( $44.1 \%$ v. $36.6 \%)$; fewer used over-the-counter medications $(59.4 \%$ v. $68.0 \%)$ or intended to consult a doctor in future episodes. Steam inhalation reduced headache but had no significant effect on other outcomes. The proportion of participants who had adverse effects was the same in both intervention groups.

Interpretation: Advice to use steam inhalation for chronic or recurrent sinus symptoms in primary care was not effective. A similar strategy to use nasal irrigation was less effective than prior evidence suggested, but it provided some symptomatic benefit. Trial registration: ISRCTN, no. 88204146.
$\mathrm{R}$ hinosinusitis probably affects more than 25 million Americans and 2.5 million Canadians. ${ }^{1}$ Quality of life of patients with chronic or recurrent sinusitis has been reported to be similar to congestive heart disease and chronic pulmonary disease. ${ }^{2}$ Antibiotics are prescribed for nearly all patients with sinusitis, ${ }^{3}$ but the evidence is modest $t^{4}$ and an international priority is to contain antibiotic resistance. ${ }^{5}$ Steam inhalation is widely advocated in rhinosinusitis, but a Cochrane review of steam for the "common cold" found equivocal evidence, ${ }^{6}$ and a recent primary care trial found no benefit and some harm (mild thermal injury) for pragmatic advice to inhale steam twice daily for a range of respiratory tract infections. ${ }^{7}$ The Cochrane review of nasal saline irrigation reported benefit. ${ }^{8}$ However, most of the trials were small, mainly from secondary care settings, and the review documented symptom data from only 129 participants, with high heterogeneity. Two small randomized controlled trials included some participants from primary care settings. ${ }^{9,10}$ One of the studies compared a gravity-based nasal irrigation device with routine care among 76 participants mainly from primary care settings; it found that symptoms im- 
proved very little in the control group (by 1 point on the Rhinosinusitis Disability Index [RSDI] converted to a 100-point scale), as compared with a 14-point improvement in the irrigation group. ${ }^{9}$ The other (published since the Cochrane review) compared a positive-pressure squeeze bottle with saline nasal spray among 121 volunteers from various sources and found an 8.5-point improvement in the control group, as compared with a 15 -point improvement in the irrigation group. ${ }^{10}$

We conducted a large pragmatic randomized controlled trial of the effectiveness of brief advice to use nasal irrigation or steam inhalation in routine primary care for chronic or recurrent sinus symptoms.

\section{Methods}

\section{Study design and setting}

We conducted a parallel-group, patient-level randomized controlled trial with an equal allocation ratio between Feb. 11, 2009, and June 30, 2014. Primary care practices near the study centre in Southampton, England, were invited to participate. There were no exclusion criteria for practices. Adults identified from the computerized registers from 72 primary care practices were sent letters inviting them to attend a recruitment clinic run by practice nurses only if they reported "moderate to severe impact of sinus symptoms on their quality of life." Nurses assessed eligibility, obtained consent and randomly assigned patients to 1 of 4 advice strategies.

The study design was approved by the Hampshire Research Ethics Committee B.

\section{Participants}

We selected patients using pragmatic inclusion criteria that matched those of the Cochrane review: ${ }^{8}$ age $18-65$ years; 2 episodes of acute sinusitis or 1 episode of chronic sinusitis as the reason for the encounter recorded in the medical records in the 3 years before enrolment; and a report of "moderate to severe" impact of sinus symptoms on quality of life.

We excluded patients who were unable to complete outcome measures (e.g., language barrier, too unwell, mental incapacity), had head or neck cancer, had HIV infection, were receiving immunosuppressive treatment, had cystic fibrosis, were pregnant or breastfeeding, or had other nasal disorders (e.g., polyps, and poor gag or swallow reflexes).

\section{Interventions}

We randomly assigned participants to 1 of 4 advice strategies defined by 2 interventions using a $2 \times 2$ factorial design (nasal irrigation $v$. no nasal irrigation, and steam inhalation v. no steam inhalation).

Usual care: All of the study participants had access to usual care. The use of medications or referral was at the discretion of the patient's physician according to his or her normal practice (i.e., not standardized).

Nasal saline irrigation: Participants were randomly assigned to receive advice to use nasal saline irrigation daily or no such advice. They were given verbal instructions and a link to watch a demonstration video on YouTube. They were given a neti pot (SinuCleanse Neti Pot, Ascent Consumer Products) and asked to irrigate their nose $(150 \mathrm{~mL}$ through each nostril) daily for 6 months. Patients made their own buffered $2.0 \%$ saline irrigation solution every 1 to 2 days comprising 1 teaspoon $(5 \mathrm{~mL})$ of salt (heaped), a half teaspoon $(2.5 \mathrm{~mL})$ of baking soda and 1 pint $(473 \mathrm{~mL})$ of tap water; how to do this was also shown on the video. We chose this particular intervention based on the provisional evidence from a previous randomized controlled trial in primary care. ${ }^{9}$

Steam inhalation: Participants were also randomly assigned to receive advice to use steam inhalation daily or no such advice. Those advised to use this intervention were asked to inhale steam for 5 minutes each day by placing a towel over their head while standing over a bowl of recently boiled water. This intervention was chosen for its wide availability and ease of use; the advice sheet did not mention use of a particular commercial steaming device.

Combination treatment: This group included the participants who were randomly assigned to receive advice to perform both daily nasal irrigation and daily steam inhalation, as described above.

\section{Randomization}

With the use of computer-generated random numbers, patients were randomly assigned to 1 of 4 pragmatic advice strategies contained in opaque sealed numbered envelopes. Sealed envelopes were used for 2 reasons: (a) because of the complex factorial design, envelopes facilitated immediate access to the correct structured advice sheets for each group (which ensured robust group differentiation) and helped simplify logistics for recruiters; and (b) with attention to equipoise, this method has resulted in robust randomization in several studies. ${ }^{711-13}$ In our study, there was no evidence of selective use of numbered envelopes or of meaningful difference in group characteristics.

Because of the nature of the interventions, it was not possible to conceal the group allocation from the participants and health care providers. 


\section{Outcome measures}

The primary outcome measure was the validated RSDI. ${ }^{14}$ We chose this measure because it permitted comparisons with findings from a previous US primary care trial. ${ }^{9}$ Three months was the primary follow-up period specified in the funding application; 6 months was included to document longer term effects.

The secondary outcome measures were the 20-item Sino-Nasal Outcome Test (SNOT-20): ${ }^{15}$ a single-item sinus severity assessment; ${ }^{9}$ severity of respiratory symptoms (as determined by the number of days feeling unwell with respiratory tract infections or sinusitis); ${ }^{16}$ reported use of over-the-counter medications, and reported headaches and adverse effects (e.g., nosebleeds, nasal burning or stinging); the EuroQol 5-dimension (EQ-5D) health-related quality-of-life index; antibiotic prescription and visits to primary care physician; and belief in antibiotics and belief in the need to see the doctor in future episodes. A costeffectiveness analysis will be reported elsewhere.

The RSDI, SNOT-20, single-item sinus severity assessment and EQ-5D were completed at baseline, 3 and 6 months. Information on respiratory and sinus symptoms, belief in the need to see the doctor, adverse effects and use of overthe-counter medications was obtained at 3 and 6 months. Review of medical records for antibiotic use and physician visits was done at 6 months.

\section{Statistical analysis}

To detect an interaction of 10 points in the RSDI between intervention groups, we estimated that we would need to power the study to detect a 5-point (about 0.36 standard deviation) main effect. This would require a minimum of 125 patients per group, or 316 in total, to allow for 4 study groups, $80 \%$ power, an $\alpha$ value of 0.05 and $80 \%$ follow-up. Early pilot work suggested that compliance and attrition might be important issues. We calculated that we would need to recruit 1190 patients $(250 /[0.3 \times 0.7])$ if $30 \%$ complied and we achieved $70 \%$ follow-up at 6 months, 894 patients $(250 /[0.4 \times 0.7])$ if $40 \%$ complied, and $716(250 /[0.5 \times 0.7])$ if $50 \%$ complied. Our minimum target, therefore, was 716 participants. Large samples also provided power for key exploratory secondary analyses (described below).

There were no interim analyses or rules for stopping the study. For missing data, we used multiple imputation (100 imputations) by chained equation model in Stata, using participant baseline characteristics, the outcome variables and the randomization group. We controlled for baseline values in the multivariate linear regression models. Because the interaction term between the 2 interventions was not signifi- cant for any outcome, we estimated the main effects of each intervention after controlling for the other intervention. We built models using backward variable selection, retaining the variables that were associated with the outcome at $p \leq 0.2$.

Key exploratory secondary analyses were specified in advance: (a) the number of participants achieving a 10-point reduction in RSDI score, which was estimated to be the minimal clinically important difference in the context of surgical trials; ${ }^{17}$ (b) the physical subscale of the RSDI (where we anticipated the greatest impact) and the number of participants achieving a clinically important 3.8-point reduction in the score for this subscale; and (c) other subgroups (effect of RSDI score above the median, history of allergic rhinitis, higher deprivation score, age above the median, longer duration of sinus symptoms [ $>15 \mathrm{yr}$ ], use of topical nasal steroids, and sex-specific effects).

\section{Changes to the protocol}

We increased the planned sample size to assess the impact of noncompliance, and we modified the randomization protocol (see above). We originally did not have permission from the ethics committee to collect the RSDI data by phone, but we gained approval half-way through the trial because follow-up rates were too low. The primary analysis was initially intended for participants with complete data, but because of lower follow-up $(<80 \%)$, we used multiple imputation to avoid the unlikely assumption that data were missing completely at random.

Following peer review, we performed a posthoc secondary analysis among participants who used nasal corticosteroids. Because we did not specify the timing of nasal irrigation, it is possible that patients who irrigated following corticosteroid use could have lessened the net benefit of irrigation.

\section{Results}

A total of 961 eligible patients agreed to participate and were randomly assigned to the study groups; of these, $871(90.6 \%)$ provided baseline data (Figure 1). The study groups were well balanced (Table 1). Overall, the RSDI was completed by 671 of the particpants at 3 months and by 623 at 6 months. Because there was no evidence of a significant interaction between intervention groups for either RSDI or SNOT-20, the main results are presented by factorial groups (nasal irrigation v. no irrigation; steam inhalation v. no steam inhalation).

At 3 months, the group advised to perform nasal irrigation reported doing the intervention for a median of 20 (interquartile range [IQR] 
5-30) days in the preceding month. Those in the steam inhalation group also reported doing the intervention for a median of 20 (IQR 6-30) days in the preceding month.
Participants' RSDI scores improved more with nasal irrigation than with no nasal irrigation (crude change in score at 3 mo -7.42 v. -5.23 ). After multiple imputation, the estimated adjusted

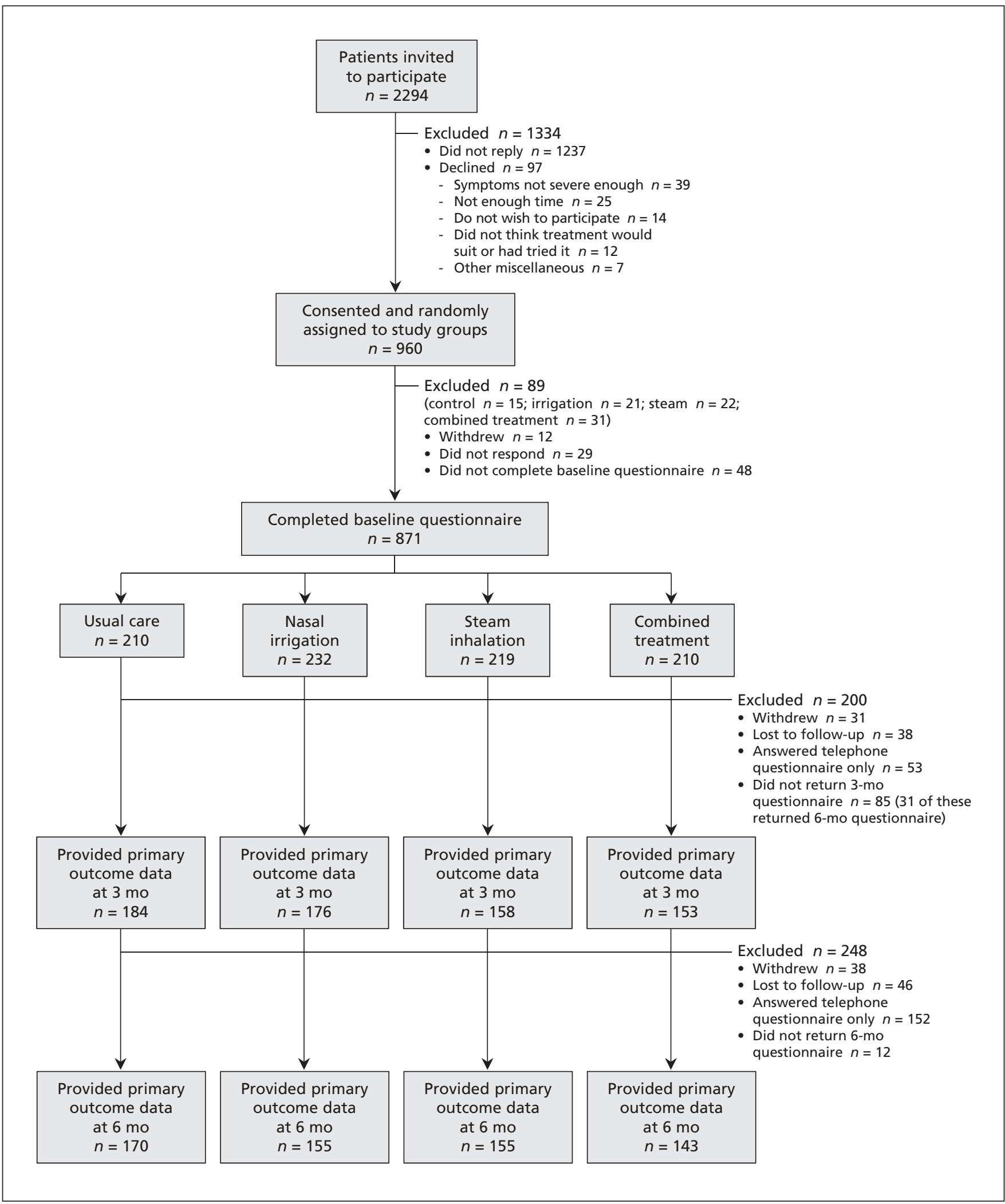

Figure 1: Selection of patients for the study. 
mean difference between groups was -2.51 (95\% confidence interval $[\mathrm{CI}]-4.65$ to -0.37 ) at 3 months and -2.41 (95\% CI -4.66 to -0.16$)$ at 6 months (Tables 2 and 3). The adjusted estimate differed slightly from the crude estimate because of better control of the small differences in confounding variables between groups. By 6 months, significantly more patients maintained a 10-point clinically important improvement in the RSDI score with nasal irrigation $(44.1 \% \mathrm{v}$. 36.6\%; Table S1 in Appendix 1, available at www.cmaj.ca/lookup/suppl/doi:10.1503/

cmaj.160362/-/DC1), mostly in the physical subscale of the RSDI (Tables S2 and S3 in Appendix 1). There was no effect of steam inhalation (see Table 3). The analysis of complete cases was similar to the imputed analysis, although the imputed analysis was slightly more conservative.
Although there were no significant interactions between interventions, the benefit of nasal irrigation at 3 and 6 months occurred mostly in the combined treatment group (Appendix 1).

There were no significant differences in the SNOT-20 scores for either intervention at 3 or 6 months (Table 3). Compared with those who did not use nasal irrigation, participants in the nasal irrigation group were more likely to agree by 6 months that they would not visit a doctor for subsequent sinus symptoms (mean difference in score on 7-point Likert scale, $0.30,95 \%$ CI 0.08 to 0.53 ; Table 4) and less likely to report headache at 3 months $(72.0 \%$ v. $81.7 \%, p=0.004$; Table 5). Nasal irrigation resulted in less use of over-the-counter medications $(60 \%$ v. $67.4 \%$, $p=0.051$ ) (Table 5). There was no difference in the number of respiratory infections reported in

Table 1: Baseline characteristics of patients with chronic or recurrent sinus symptoms, by factorial group and randomization group

\begin{tabular}{|c|c|c|c|c|c|c|c|c|}
\hline \multirow[b]{3}{*}{ Characteristic } & \multicolumn{8}{|c|}{ Factorial group; no. $(\%)$ or mean \pm SD } \\
\hline & \multicolumn{4}{|c|}{ Participants with baseline primary outcome data } & \multicolumn{4}{|c|}{ All participants } \\
\hline & $\begin{array}{l}\text { No nasal } \\
\text { irrigation }\end{array}$ & $\begin{array}{l}\text { Nasal } \\
\text { irrigation }\end{array}$ & $\begin{array}{l}\text { No steam } \\
\text { inhalation }\end{array}$ & $\begin{array}{l}\text { Steam } \\
\text { inhalation }\end{array}$ & $\begin{array}{l}\text { No nasal } \\
\text { irrigation }\end{array}$ & $\begin{array}{c}\text { Nasal } \\
\text { irrigation }\end{array}$ & $\begin{array}{l}\text { No steam } \\
\text { inhalation }\end{array}$ & $\begin{array}{l}\text { Steam } \\
\text { inhalation }\end{array}$ \\
\hline Female sex & 299/428 (69.9) & $317 / 442(71.7)$ & $311 / 442(70.4)$ & $305 / 428(71.3)$ & $324 / 465(69.7)$ & $358 / 494(72.5)$ & $337 / 478(70.5)$ & $345 / 481(71.7)$ \\
\hline Age, yr & $52.46 \pm 13.91$ & $52.46 \pm 14.31$ & $52.21 \pm 13.72$ & $52.71 \pm 14.50$ & $51.88 \pm 13.95$ & $51.60 \pm 14.48$ & $51.70 \pm 13.68$ & $51.77 \pm 14.73$ \\
\hline Age left school, yr & $17.90 \pm 2.89$ & $17.89 \pm 3.02$ & $18.03 \pm 3.08$ & $17.76 \pm 2.82$ & $17.91 \pm 2.89$ & $17.89 \pm 3.02$ & $18.03 \pm 3.08$ & $17.75 \pm 2.81$ \\
\hline $\begin{array}{l}\text { History of allergic } \\
\text { rhinitis or allergy }\end{array}$ & $219 / 414(52.9)$ & $223 / 431(51.7)$ & $211 / 430(49.1)$ & $231 / 415(55.7)$ & $231 / 441(52.4)$ & $241 / 470(51.3)$ & $221 / 456(48.5)$ & $251 / 455(55.2)$ \\
\hline Never smoked & 195/384 (50.8) & 189/393 (48.1) & 204/393 (51.9) & 180/384 (46.9) & 206/413 (49.9) & 206/432 (47.7) & $216 / 419(51.6)$ & $196 / 426(46.0)$ \\
\hline IMD score & $21.29 \pm 13.02$ & $21.63 \pm 13.31$ & $21.54 \pm 13.25$ & $21.37 \pm 13.08$ & $22.34 \pm 12.96$ & $22.97 \pm 13.16$ & $22.52 \pm 13.16$ & $22.80 \pm 12.96$ \\
\hline $\begin{array}{l}\text { Baseline severity } \\
\text { (single-item sinus } \\
\text { severity assessment) }\end{array}$ & $2.77 \pm 0.96$ & $2.76 \pm 0.90$ & $2.73 \pm 0.94$ & $2.81 \pm 0.91$ & $2.77 \pm 0.95$ & $2.77 \pm 0.90$ & $2.74 \pm 0.94$ & $2.81 \pm 0.90$ \\
\hline \multirow[t]{3}{*}{$\begin{array}{l}\text { Duration of sinus } \\
\text { problems, yr }\end{array}$} & $19.36 \pm 16.21$ & $18.70 \pm 15.62$ & $19.55 \pm 16.47$ & $18.48 \pm 15.32$ & $19.22 \pm 16.26$ & $18.01 \pm 15.43$ & $19.10 \pm 16.28$ & $18.12 \pm 15.42$ \\
\hline & \multicolumn{8}{|c|}{ Randomization group; no. (\%) or mean \pm SD } \\
\hline & \multicolumn{4}{|c|}{ Participants with baseline primary outcome data } & \multicolumn{4}{|c|}{ All participants } \\
\hline Characteristic & $\begin{array}{l}\text { Usual } \\
\text { care }\end{array}$ & $\begin{array}{l}\text { Nasal } \\
\text { irrigation }\end{array}$ & $\begin{array}{l}\text { Steam } \\
\text { inhalation }\end{array}$ & $\begin{array}{l}\text { Combined } \\
\text { treatment }\end{array}$ & $\begin{array}{l}\text { Usual } \\
\text { care }\end{array}$ & $\begin{array}{l}\text { Nasal } \\
\text { irrigation }\end{array}$ & $\begin{array}{l}\text { Steam } \\
\text { inhalation }\end{array}$ & $\begin{array}{l}\text { Combined } \\
\text { treatment }\end{array}$ \\
\hline Female sex & $151 / 210(71.9)$ & $160 / 232(69.0)$ & $148 / 218(67.9)$ & $157 / 210(74.8)$ & $160 / 225(71.1)$ & $177 / 253(70.0)$ & $164 / 240(68.3)$ & $181 / 241(75.1)$ \\
\hline Age, yr & $52.60 \pm 13.66$ & $51.85 \pm 13.80$ & $52.31 \pm 14.18$ & $53.13 \pm 14.85$ & $52.10 \pm 13.61$ & $51.35 \pm 13.77$ & $51.67 \pm 14.29$ & $51.87 \pm 15.20$ \\
\hline Age left school, yr & $18.01 \pm 2.95$ & $18.05 \pm 3.20$ & $17.80 \pm 2.83$ & $17.71 \pm 2.81$ & $18.00 \pm 2.95$ & $18.05 \pm 3.20$ & $17.81 \pm 2.82$ & $17.70 \pm 2.80$ \\
\hline $\begin{array}{l}\text { History of allergic } \\
\text { rhinitis or allergy }\end{array}$ & $107 / 203(52.7)$ & $104 / 227(45.8)$ & $112 / 211(53.1)$ & $119 / 204(58.3)$ & $111 / 212(52.4)$ & $110 / 244(45.1)$ & $120 / 229(52.4)$ & $131 / 226(58.0)$ \\
\hline Never smoked & $98 / 187(52.4)$ & $106 / 206(51.5)$ & 97/197 (49.2) & $83 / 187$ (44.4) & $102 / 196(52.0)$ & $114 / 223(51.1)$ & $104 / 217(47.9)$ & $92 / 209(44.0)$ \\
\hline IMD score & $21.15 \pm 13.32$ & $21.90 \pm 13.20$ & $21.42 \pm 12.74$ & $21.32 \pm 13.46$ & $22.05 \pm 13.27$ & $22.95 \pm 13.07$ & $22.62 \pm 12.68$ & $22.98 \pm 13.27$ \\
\hline $\begin{array}{l}\text { Baseline severity } \\
\text { (single-item sinus } \\
\text { severity assessment) }\end{array}$ & $2.72 \pm 0.95$ & $2.74 \pm 0.93$ & $2.82 \pm 0.96$ & $2.78 \pm 0.86$ & NA & NA & NA & NA \\
\hline $\begin{array}{l}\text { Duration of sinus } \\
\text { problems, yr }\end{array}$ & $20.01 \pm 17.05$ & $19.14 \pm 15.95$ & $18.75 \pm 15.39$ & $18.20 \pm 15.27$ & $19.72 \pm 16.92$ & $18.55 \pm 15.70$ & $18.78 \pm 15.68$ & $17.43 \pm 15.14$ \\
\hline
\end{tabular}


the month before follow-up (median 1 for all groups at 3 and $6 \mathrm{mo}$ ). Nasal irrigation did not significantly reduce the number of days participants felt unwell with respiratory tract infections at 3 or 6 months ( 1 v. $2 \mathrm{~d}$ at $3 \mathrm{mo}$, and $2 \mathrm{v} .3 \mathrm{~d}$ at 6 mo, respectively) (Table 6). Nasal irrigation significantly reduced the number of days of feeling unwell with sinusitis at 6 months (4 v. $7 \mathrm{~d}$ without nasal irrigation) (Table 6). There was no effect of steam inhalation on the secondary outcomes except headache (Table 5).

There was no difference in the proportions of participants who experienced adverse effects (e.g., nose bleeds, nasal soreness or burning) in either intervention group (Table 5).

\section{Prespecified subgroups}

There was no evidence of a differential effect of either intervention in the clinical subgroups defined before analysis (Tables S5, S6a and S6b, Appendix 1).

Following peer review, we assessed interaction for nasal irrigation among individuals who used nasal corticosteroids. We found no evidence of a lesser effect: the interaction term for the imputed dataset for RSDI scores was -2.90 (95\% CI -10.54 to 4.75 ) at 3 months and 0.37 (95\% CI -7.88 to 8.61 ) at 6 months. Furthermore, only a minority of participants used nasal corticosteroids (nasal irrigation: 9.5\% [42/442]; no irrigation: $10.0 \%$ [43/429]).

\section{Interpretation}

This is one of the few studies to address the effectiveness of brief advice to use nasal irrigation or steam inhalation for chronic or recurrent sinus symptoms, and the largest trial in any setting. Brief advice to use nasal irrigation resulted in modest improvement in the primary outcome (RSDI score), which was significant at both 3 and 6 months, and evidence of improvement in several secondary outcomes. A similar strategy to use steam inhalation was not effective.

The RSDI scores improved with nasal irrigation, but the control group's scores also improved. The 2- to 3-point difference between the irrigation and control groups, and a number needed to treat of about 13, was smaller than in 2 prior US trials (by Rabago and colleagues ${ }^{9}$ and Pynnonen and

Table 2: Participants' RSDI and SNOT-20 scores at baseline, 3 mo and 6 mo

\begin{tabular}{|c|c|c|c|c|}
\hline \multirow[b]{2}{*}{ Outcome measure* } & \multicolumn{4}{|c|}{ Factorial group; mean score \pm SD } \\
\hline & $\begin{array}{l}\text { No nasal } \\
\text { irrigation }\end{array}$ & $\begin{array}{c}\text { Nasal } \\
\text { irrigation }\end{array}$ & $\begin{array}{l}\text { No steam } \\
\text { inhalation }\end{array}$ & $\begin{array}{c}\text { Steam } \\
\text { inhalation }\end{array}$ \\
\hline \multicolumn{5}{|l|}{ RSDI } \\
\hline At baseline & $44.18 \pm 19.29$ & $43.02 \pm 20.61$ & $43.60 \pm 20.59$ & $43.58 \pm 19.32$ \\
\hline At $3 \mathrm{mo}$ & $38.95 \pm 19.65$ & $35.60 \pm 21.13$ & $37.60 \pm 20.59$ & $36.89 \pm 20.37$ \\
\hline At $6 \mathrm{mo}$ & $38.26 \pm 20.05$ & $35.06 \pm 22.33$ & $36.83 \pm 21.87$ & $36.43 \pm 20.69$ \\
\hline \multicolumn{5}{|l|}{ SNOT-20 } \\
\hline At baseline & $2.45 \pm 1.00$ & $2.37 \pm 0.95$ & $2.40 \pm 0.99$ & $2.41 \pm 0.97$ \\
\hline At $3 \mathrm{mo}$ & $2.14 \pm 1.02$ & $1.97 \pm 1.07$ & $2.07 \pm 1.04$ & $2.04 \pm 1.05$ \\
\hline At $6 \mathrm{mo}$ & $2.16 \pm 1.07$ & $2.01 \pm 1.11$ & $2.10 \pm 1.09$ & $2.07 \pm 1.10$ \\
\hline & \multicolumn{4}{|c|}{ Randomization group; mean score \pm SD } \\
\hline Outcome measure* & $\begin{array}{l}\text { Usual } \\
\text { care }\end{array}$ & $\begin{array}{c}\text { Nasal } \\
\text { irrigation }\end{array}$ & $\begin{array}{l}\text { Steam } \\
\text { inhalation }\end{array}$ & Combined treatment \\
\hline \multicolumn{5}{|l|}{ RSDI } \\
\hline At baseline & $44.26 \pm 20.02$ & $43.01 \pm 21.11$ & $44.11 \pm 18.60$ & $43.02 \pm 20.09$ \\
\hline At $3 \mathrm{mo}$ & $39.27 \pm 19.72$ & $36.09 \pm 21.22$ & $38.66 \pm 19.57$ & $35.05 \pm 21.01$ \\
\hline At $6 \mathrm{mo}$ & $38.05 \pm 20.61$ & $35.72 \pm 22.88$ & $38.45 \pm 19.58$ & $34.33 \pm 21.68$ \\
\hline \multicolumn{5}{|l|}{ SNOT-20 } \\
\hline At baseline & $2.45 \pm 1.02$ & $2.36 \pm 0.85$ & $2.44 \pm 0.98$ & $2.37 \pm 0.95$ \\
\hline At $3 \mathrm{mo}$ & $2.17 \pm 1.00$ & $1.98 \pm 1.07$ & $2.11 \pm 1.03$ & $1.96 \pm 1.06$ \\
\hline At $6 \mathrm{mo}$ & $2.17 \pm 1.06$ & $2.03 \pm 1.11$ & $2.15 \pm 1.08$ & $1.99 \pm 1.12$ \\
\hline
\end{tabular}


colleage $\left.{ }^{10}\right)$, which enrolled volunteer patients from primary care, secondary care and community settings. In the US studies, participants in the nasal irrigation groups reported changes on 100-point scales of 14 and 15 points,, ${ }^{9,10}$ as compared with 1 and 8.5 points reported by the control groups. ${ }^{9,10}$ Several factors may have contributed to the differences: Rabago and colleagues allowed participants to know their previous ratings, which may have anchored the control group responses, and provided individualized training (including video, live demonstration and coached practice to ensure proficiency), which was valued. ${ }^{18}$ Pynnonen and colleagues also allowed coached practice, and both studies had more follow-up contacts and diary monitoring. These more intensive approaches may have increased treatment effect through adherence. However, participants in our study used irrigation on most days, and the impact was the same among participants who irrigated more often. Although the number of irrigations may not explain the dis- crepancies, the quality and duration of irrigation may still be relevant. Rabago and colleagues ${ }^{9}$ assessed a more severely affected sample; however, we found no evidence of greater effectiveness among participants in our study who had higher RSDI scores at baseline. Participants in the 2 US studies were younger (10 and 6 years younger on average than our study population, respectively) and had a much shorter history of sinus complaints; therefore, symptoms may have been more amenable to change. Culturally, nasal irrigation is popular in the US, and expectations about benefit may be higher.

We found potentially important changes in other outcomes; in particular, fewer participants in the nasal irrigation group than in the noirrigation group had headaches, used over-thecounter medications and intended to consult a doctor in future episodes. Although there was no significant difference in either physician visits or antibiotic use, as might be expected over only a

\begin{tabular}{|c|c|c|c|c|}
\hline \multirow[b]{2}{*}{ Variable } & \multicolumn{2}{|c|}{ Mean difference in RSDI scores $(95 \% \mathrm{Cl})$} & \multicolumn{2}{|c|}{ Mean difference in SNOT-20 scores $(95 \% \mathrm{Cl})$} \\
\hline & At 3 mo & At $6 \mathrm{mo}$ & At 3 mo & At 6 mo \\
\hline \multicolumn{5}{|l|}{$\begin{array}{l}\text { Nasal irrigation } \\
\text { (v. no irrigation) }\end{array}$} \\
\hline Crude & $-2.53(-4.68$ to -0.39$)$ & $-2.34(-4.49$ to -0.07$)$ & $-0.12(-0.25$ to 0.01$)$ & $-0.10(-0.24$ to 0.03$)$ \\
\hline Adjusted & $-2.51(-4.65$ to -0.37$)$ & $-2.41(-4.66$ to -0.16$)$ & $-0.12(-0.25$ to 0.004$)$ & $-0.11(-0.25$ to 0.03$)$ \\
\hline \multicolumn{5}{|c|}{$\begin{array}{l}\text { Steam inhalation } \\
\text { (v. no steam inhalation) }\end{array}$} \\
\hline Crude & $-0.78(-2.92$ to 1.36$)$ & $-0.46(-2.75$ to 1.84$)$ & $-0.04(-0.17$ to 0.09$)$ & $-0.03(-0.17$ to 0.10$)$ \\
\hline Adjusted & $-0.73(-2.85$ to 1.39$)$ & $-0.60(-2.87$ to 1.68$)$ & $-0.05(-0.17$ to 0.08$)$ & $-0.04(-0.17$ to 0.10$)$ \\
\hline Interaction term & $-0.53(-4.81$ to 3.65$)$ & $-1.91(-6.34$ to 2.52$)$ & $0.02(-0.22$ to 0.27$)$ & $-0.03(-0.30$ to 0.23$)$ \\
\hline
\end{tabular}

Table 4: Impact of interventions on single-item sinus severity assessment, ${ }^{9}$ and attitudes toward antibiotics and need to visit a doctor

\begin{tabular}{|c|c|c|c|c|c|}
\hline Variable & $\begin{array}{c}\text { Sinus severity } \\
\text { assessment at } 3 \text { mo }\end{array}$ & $\begin{array}{c}\text { Sinus severity } \\
\text { assessment at } 6 \text { mo }\end{array}$ & $\begin{array}{c}\text { Belief in } \\
\text { antibiotics* }\end{array}$ & $\begin{array}{l}\text { Would not visit } \\
\text { doctor next time, * } \\
\text { at } 3 \text { mo }\end{array}$ & $\begin{array}{l}\text { Would not visit } \\
\text { doctor next time, * } \\
\text { at } 6 \text { mo }\end{array}$ \\
\hline \multicolumn{6}{|c|}{$\begin{array}{l}\text { Nasal irrigation } \\
\text { (v. no irrigation) }\end{array}$} \\
\hline Adjusted & $0.07(-0.17$ to 0.31$)$ & $0.22(-0.04$ to 0.48$)$ & $0.09(-0.13$ to 0.30$)$ & 0.22 (-0.01 to 0.45$)$ & 0.32 (0.09 to 0.54$)$ \\
\hline \multicolumn{6}{|c|}{$\begin{array}{l}\text { Steam inhalation } \\
\text { (v. no steam nhalation) }\end{array}$} \\
\hline Crude & $0.05(-0.20$ to 0.30$)$ & $0.11(-0.15$ to 0.37$)$ & $-0.11(-0.34$ to 0.11$)$ & $-0.04(-0.26$ to 0.20$)$ & $0.08(-0.16$ to 0.31$)$ \\
\hline Adjusted & 0.06 (-0.18 to 0.31$)$ & $0.11(-0.15$ to 0.37$)$ & $-0.12(-0.34$ to 0.10$)$ & $-0.01(-0.24$ to 0.22$)$ & 0.08 (-0.15 to 0.31$)$ \\
\hline
\end{tabular}


Table 5: Secondary outcomes and adverse effects during prior month reported at 3 mo and 6 mo

\begin{tabular}{|c|c|c|c|c|}
\hline Variable & $\begin{array}{l}\text { No nasal } \\
\text { irrigation }\end{array}$ & $\begin{array}{c}\text { Nasal } \\
\text { irrigation }\end{array}$ & $\begin{array}{l}\text { No steam } \\
\text { inhalation }\end{array}$ & $\begin{array}{c}\text { Steam } \\
\text { inhalation }\end{array}$ \\
\hline \multicolumn{5}{|l|}{ Reported at 3 mo } \\
\hline Headache, \% & 81.7 & 72.0 & 80.4 & 73.1 \\
\hline Univariate RR $(95 \% \mathrm{Cl})$ & 1.00 & 0.88 (0.81 to 0.95$)$ & 1.00 & 0.90 (0.83 to 0.98$)$ \\
\hline Adjusted RR (95\% Cl) & 1.00 & 0.88 (0.81 to 0.96$)$ & 1.00 & 0.91 (0.84 to 0.99$)$ \\
\hline Adverse effects, ${ }^{*} \%$ & 65.6 & 64.2 & 66.8 & 62.9 \\
\hline Univariate RR $(95 \% \mathrm{Cl})$ & 1.00 & 0.98 (0.88 to 1.10$)$ & 1.00 & 0.94 (0.83 to 1.05$)$ \\
\hline Adjusted RR (95\% Cl) & 1.00 & 0.98 (0.88 to 1.09$)$ & 1.00 & 0.92 (0.82 to 1.03$)$ \\
\hline Use of OTC treatment, $\dagger \%$ & 67.4 & 60.0 & 64.3 & 62.9 \\
\hline Univariate RR $(95 \% \mathrm{Cl})$ & 1.00 & 0.89 (0.80 to 1.00$)$ & 1.00 & $0.98(0.87$ to 1.10$)$ \\
\hline Adjusted RR (95\% Cl) & 1.00 & 0.90 (0.81 to 1.00$)$ & 1.00 & $0.99(0.89$ to 1.11$)$ \\
\hline \multicolumn{5}{|l|}{ Reported at 6 mo } \\
\hline Headache, \% & 79.8 & 73.9 & 77.3 & 76.2 \\
\hline Univariate RR $(95 \% \mathrm{Cl})$ & 1.00 & 0.93 (0.85 to 1.01$)$ & 1.00 & 0.98 (0.90 to 1.07$)$ \\
\hline Adjusted RR (95\% Cl) & 1.00 & 0.93 (0.85 to 1.01$)$ & 1.00 & 0.99 (0.91 to 1.08$)$ \\
\hline Adverse effects, $* \%$ & 66.7 & 60.6 & 63.9 & 63.3 \\
\hline Univariate RR $(95 \% \mathrm{Cl})$ & 1.00 & 0.91 (0.81 to 1.02 ) & 1.00 & $0.99(0.87$ to 1.13$)$ \\
\hline Adjusted RR $(95 \% \mathrm{Cl})$ & 1.00 & 0.90 (0.80 to 1.01$)$ & 1.00 & $0.98(0.86$ to 1.12$)$ \\
\hline Use of OTC treatment, $\dagger \%$ & 68.0 & 59.4 & 64.8 & 62.4 \\
\hline Univariate RR $(95 \% \mathrm{Cl})$ & 1.00 & 0.87 (0.78 to 0.98$)$ & 1.00 & 0.96 (0.85 to 1.08$)$ \\
\hline Adjusted RR $(95 \% \mathrm{Cl})$ & 1.00 & 0.87 (0.78 to 0.97$)$ & 1.00 & 0.95 (0.85 to 1.07$)$ \\
\hline \multicolumn{5}{|c|}{$\begin{array}{l}\text { Note: } \mathrm{Cl}=\text { confidence interval, OTC = over the counter, } \mathrm{RR}=\text { risk ratio. } \\
\text { *Includes nosebleeds, nasal burning or stinging, soreness. } \\
\text { tParticipants were asked at } 3 \text { mo and } 6 \text { mo whether they had used an acetylsalicylic acid oral rinse, benzydamine hydrochloride } \\
\text { oral rinse, cough medicine, mentholated topical ointment, echinacea, lozenges or nasal sprays in the preceding month. }\end{array}$} \\
\hline
\end{tabular}

Table 6: Number of days feeling unwell with symptoms of respiratory tract infections or sinusitis in prior month reported at 3 mo and 6 mo

\begin{tabular}{|c|c|c|c|c|}
\hline Variable & $\begin{array}{c}\text { No nasal } \\
\text { irrigation }\end{array}$ & $\begin{array}{c}\text { Nasal } \\
\text { irrigation }\end{array}$ & $\begin{array}{l}\text { No steam } \\
\text { inhalation }\end{array}$ & $\begin{array}{l}\text { Steam } \\
\text { inhalation }\end{array}$ \\
\hline \multicolumn{5}{|l|}{ RTI symptoms* } \\
\hline Days unwell at 3 mo, median (IQR) & 2 (0 to 7$)$ & 1 (0 to 7$)$ & $2(0$ to 7$)$ & $2(0$ to 8$)$ \\
\hline Univariate RR $(95 \% \mathrm{Cl})$ & 1.00 & $0.93(0.76,1.14)$ & 1.00 & 1.06 (0.86 to 1.29$)$ \\
\hline Adjusted RR (95\% CI) & 1.00 & 0.95 (0.77 to 1.16$)$ & 1.00 & 1.10 (0.89 to 1.35$)$ \\
\hline Days unwell at 6 mo, median (IQR) & $3(0$ to 8$)$ & $2(0$ to 7$)$ & 2 (0 to 7$)$ & $2(0$ to 8$)$ \\
\hline Univariate RR $(95 \% \mathrm{Cl})$ & 1.00 & 0.96 (0.78 to 1.19$)$ & 1.00 & 1.17 (0.94 to 1.45$)$ \\
\hline Adjusted RR $(95 \% \mathrm{Cl})$ & 1.00 & $0.96(0.77$ to 1.18$)$ & 1.00 & 1.18 (0.95 to 1.46$)$ \\
\hline \multicolumn{5}{|l|}{ Sinusitis symptoms } \\
\hline Days unwell at 3 mo, median (IQR) & $6(1$ to 18$)$ & 5 (0 to 15$)$ & $6(1$ to 17$)$ & $6(0$ to 18$)$ \\
\hline Univariate RR $(95 \% \mathrm{Cl})$ & 1.00 & 0.88 (0.75 to 1.03$)$ & 1.00 & 0.97 (0.83 to 1.14$)$ \\
\hline Adjusted RR (95\% CI) & 1.00 & $0.88(0.75$ to 1.03$)$ & 1.00 & 0.95 (0.81 to 1.12$)$ \\
\hline Days unwell at 6 mo, median (IQR) & 7 (0 to 18$)$ & 4 (0 to 14$)$ & 5 (0 to 14$)$ & $6(0$ to 18$)$ \\
\hline Univariate RR $(95 \% \mathrm{Cl})$ & 1.00 & 0.82 (0.69 to 0.98$)$ & 1.00 & 1.02 (0.86 to 1.21$)$ \\
\hline Adjusted RR (95\% CI) & 1.00 & 0.81 (0.68 to 0.96$)$ & 1.00 & 1.02 (0.85 to 1.22$)$ \\
\hline
\end{tabular}


6-month follow-up period, our findings concerning consultations are important in the longer term, given antibiotic use increases the risk of antimicrobial resistance.

Apart from being associated with fewer headaches, the strategy of advising patients to use steam inhalation was ineffective in our study, a finding that matches the limited impact in acute coryzal illness ${ }^{6}$ or in acute respiratory tract infections more generally. ${ }^{7}$ However, advice to use nasal irrigation was beneficial mostly in the combined treatment group, which suggests a possible role for steam inhalation in supporting nasal irrigation. There was no evidence of the modest harm (minor thermal injury) previously observed among patients using steam inhalation for acute respiratory tract infections. ${ }^{7}$ We chose a pragmatic target of steam inhalation once a day, because intrusive interventions that require more effort and offer limited benefit are not maintained. Whether a more intensive approach to this intervention might be beneficial is unclear.

\section{Limitations}

The proportion of patients who consented to participate in the study but did not provide a baseline RSDI score $(9.4 \%)$ was much higher than in our previous studies. This suggests that we may not have engaged individuals adequately when obtaining their consent; despite feedback to the practices, there was no improvement during the trial. However, the participants who did return the questionnaire were almost identical to the sample who consented.

Slightly less than $80 \%$ follow-up was achieved, but we found little evidence of attrition bias using multiple imputation.

The primary outcome was self-reported, but the impact on symptoms can be documented only by self-report, and the ineffectiveness of steam inhalation suggests that generalized reporting bias was unlikely. Furthermore, meaningful changes also occurred in other outcomes.

The rate of uptake to the baseline appointment was more than $40 \%$, which is good for a cold-call invitation, and the participants were our intended target (i.e., sufficiently concerned about their symptoms to be motivated for self-management).

Randomization envelopes were chosen for good logistic reasons, but equally they can be used to undermine randomization. However, there was no evidence of either selective use of envelopes or significant differences in characteristics between groups, which suggests that the randomization worked. We also controlled for a range of baseline characteristics.

We chose chronic or recurrent acute sinus symptoms, so the sample was heterogeneous (e.g., some participants had allergic rhinitis, and the duration of prior illness varied). However, these criteria were similar to those in prior studies and in the Cochrane review, ${ }^{8}$ and there was no evidence of substantial selective treatment effects in any clinical subgroup.

The inclusion criteria were based on the clinical diagnosis recorded by the doctor, and participants reported substantial impact on their quality of life. It is possible that a more tightly defined group might have benefitted more from the interventions.

The timing of nasal irrigation was not specified, but we found no evidence of a lesser effect among patients who used nasal corticosteroids.

\section{Conclusion}

Brief advice to use nasal irrigation in routine primary care for chronic or recurrent sinus symptoms was less effective than prior evidence suggested, but it resulted in reduced overall symptom burden, headache, use of over-the-counter medications and the perceived need to consult primary care physicians in future episodes. Steam inhalation had no consistent benefits. Future research on nasal irrigation should address how much coaching is needed, the role of expectations and its place in relieving symptoms of acute sinusitis.

\section{References}

1. Desrosiers M, Evans GA, Keith PK, et al. Canadian clinical practice guidelines for acute and chronic rhinosinusitis. Allergy Asthma Clin Immunol 2011;7:2.

2. Glicklich RE, Metson R. The health impact of chronic sinusitis in patients seeking otolaryngologic care. Otolaryngol Head Neck Surg 1995;113:104-9.

3. Petersen I, Johnson A, Islam A, et al. Protective effect of antibiotics against serious complications of common respiratory tract infections: retrospective cohort study with the UK General Practice Research Database. BMJ 2007:335:982.

4. Ahovuo-Saloranta A, Rautakorpi U, Borisenko O, et al Antibiotics for acute maxillary sinusitis in adults. Cochrane Database Syst Rev 2014;(2):CD000243.

5. Carlet J, Jarlier V, Harbarth S, et al. Ready for a world without antibiotics? The Pensières Antibiotic Resistance Call to Action. Antimicrob Resist Infect Control 2012;1:11.

6. Singh M, Singh H. Heated, humidified air for the common cold. Cochrane Database Syst Rev 2013;(6):CD001728.

7. Little P, Moore M, Kelly J, et al. Ibuprofen, paracetamol, and steam for patients with respiratory tract infections in primary care: pragmatic randomised factorial trial. BMJ 2013;347: f6041.

8. Harvey R, Hannan S, Badia L, et al. Nasal saline irrigations for the symptoms of chronic rhinosinusitis. Cochrane Database Syst Rev 2007; (3):CD006394

9. Rabago D, Zgierska A, Mundt M, et al. Efficacy of daily hypertonic saline nasal irrigation among patients with sinusitis: a randomized controlled trial. J Fam Pract 2002;51:1049-55.

10. Pynnonen MA, Mukerji SS, Kim HM, et al. Nasal saline for chronic sinonasal symptoms: a randomized controlled trial. Arch Otolaryngol Head Neck Surg 2007;133:1115-20.

11. Little P, Williamson I, Warner G, et al. An open randomised trial of prescribing strategies for sore throat. BMJ 1997;314:722-7.

12. Little P, Gould C, Williamson I, et al. A pragmatic randomised controlled trial of two prescribing strategies for acute otitis media. BMJ 2001;322:336-42.

13. Little P, Rumsby K, Kelly J, et al. Information leaflet and antibiotic prescribing strategies for acute lower respiratory tract infection: a randomized controlled trial. JAMA 2005;293:3029-35.

14. Benninger MS, Senior BA. The development of the Rhinosinusitis Disability Index. Arch Otolaryngol Head Neck Surg 1997;123: 1175-9. 
15. Morley AD, Sharp HR. A review of sinonasal outcome scoring systems: Which is best? Clin Otolaryngol 2006;31:103-9.

16. Watson L, Little P, Williamson I, et al. Validation study of a diary for use in acute lower respiratory tract infection. Fam Pract 2001;18:553-4.

17. Soler ZM, Smith TL. Quality of life outcomes after functional endoscopic sinus surgery. Otolaryngol Clin North Am 2010; 43:605-12.

18. Rabago D, Barrett B, Marchand L, et al. Qualitative aspects of nasal irrigation use by patients with chronic sinus disease in a multi-method study. Ann Fam Med 2006;4:295-301.

Affiliations: Primary Care Group (Little, Stuart, Moore, Thomas, Johnson, Williamson), Health Economic Analyses Team (Yao, Raftery, Zhu) and Research Design Service South Central (Mullee), Primary Care and Population Sciences Unit (Leydon), University of Southampton, Southampton, UK; Patient and Public Involvement Collaborator (Richards-Hall), Southampton, UK; Department of Family Medicine and Community Health (Rabago), University of Wisconsin School of Medicine and Public Health, Madison, Wis.

Contributors: Paul Little had the original idea for the protocol, led protocol development and the funding application, supervised the running of the study centre, contributed to the analysis and led the drafting of the paper. Beth Stuart, with input from Mark Mullee, developed the analysis protocol, performed the quantitative analysis and contributed to drafting of the paper. Tammy Thomas developed the protocol, provided overall management of the study, coordinated recruitment and commented on drafts of the paper. Sophie Johnson provided coordination and data management for the Southampton study centre. Ian Williamson and Michael Moore contributed to developing the protocol for funding, the management of the study, the analysis of data and the drafting of the paper. Guiqing Yao, James Raftery and Shihua Zhu developed the protocol for analysis of the medical records data and contributed to the drafting of the paper. James Raftery contributed to developing the protocol for funding and the management of the study, supervised the analysis of data on resource use and contributed to the drafting of the paper. Gerry Leydon, David Rabago and Samantha Richards-Hall contributed to developing or refining the study protocol, the management of the study and the data analysis, and commented on drafts of the paper. All of the authors approved the final version of the article to be published and agreed to act as guarantors of the work.

Funding: The study was funded by a grant from the National Institute for Health Research (NIHR) under its Programme Grants for Applied Research (grant no. RP-PG-0407-10098). The views expressed are those of the authors and not necessarily those of the National Health Service, the NIHR or the Department of Health. The University of Southampton was the sponsor, but it had no role in the running of the study, the analysis or interpretation of the results, or the preparation of the manuscript.

Acknowledgements: The authors are grateful to the patients and health care professionals who contributed their time and effort and helpful insights to make the study possible. They are also grateful to the Programme Steering Committee for their support and advice throughout the study.

Data sharing: The dataset used for this analysis is available on request from Paul Little. Access may be granted by the authors after review of the proposed analysis.

SNIFS (Steam Inhalation and Nasal Irrigation for Recurrent or Chronic Sinus Symptoms) Study team: Paul Little, Beth Stuart, Mark Mullee, Tammy Thomas, Sophie Johnson, Gerry Leydon, David Rabago, Samantha Richards-Hall, Ian Williamson, Lily Yao, James Raftery, Shihua Zhu, Michael Moore; and Chris Smith, Stephen Petley and Ben HoldstockBrown, Faculty of Medicine, University of Southampton
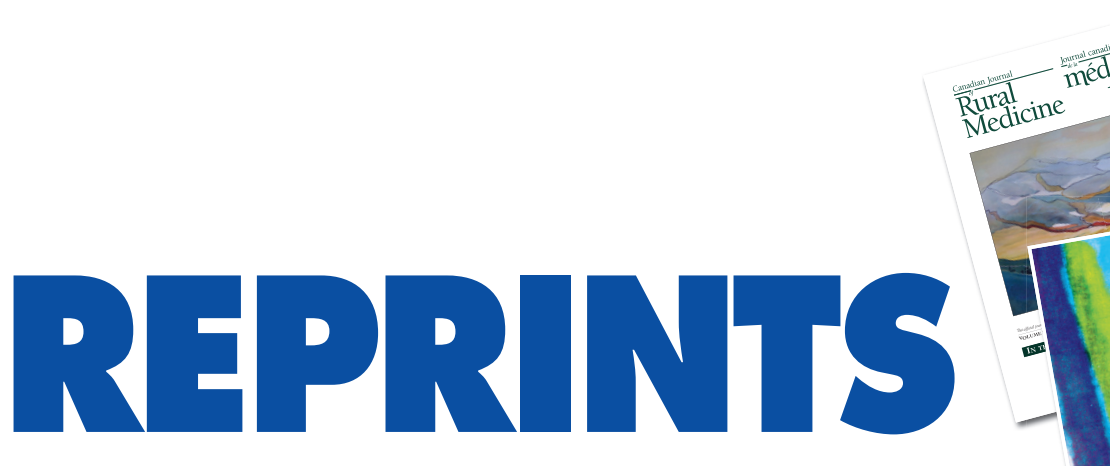

\section{We have partnered with Sheridan Press!}

To purchase commercial article reprints and e-prints or to request a quote, please contact

Matt Neiderer

Content Sales Sheridan Content Services

$800635-7181 \times 8265$ matt.neiderer@sheridan.com 